Egyptian

Orthodontic Journal

\title{
THE PATTERN OF MALOCCLUSION AMONG A SAMPLE OF SAUDI ORTHODONTIC PATIENTS IN JEDDAH
}

\author{
Zuhair A Murshid*
}

\section{ABSTRACT}

The prevalence of malocclusion in Saudi Arabian population is well recognized. Previous researchers have shown that there is an increase demand for orthodontic treatment; however those reports were limited to the districts where they were performed, and were affected by life style in these areas, however, none of these studies was performed in the western province. The aim of this study was to investigate the prevalence of malocclusion and arch form in the permanent dentition among Saudi Arabian patients in Jeddah, to serve as a database for more successful orthodontic treatment. Malocclusion was evaluated based on Angle's Classification, also arch form was studied based on Ovoid (average), Taper (narrow) and Square (broad) shape arches. The investigated sample was 84 males and 93 females with mean age of 15.3 and 15.0 year for males and females respectively. The results of the study indicated that among males Angle Class II is the most prevalent type. In the lower arch, Ovoid shape was the most prevalent arch form, while narrow shape was the most prevalent arch form in the upper arch in all subjects (percentage was higher in males). Dental midfine shift and crowding were the most prevalent variables among malocclusal features especially in females.

Keywords: Angle classification, arch form, incisor classification, malocclusion relationship.

\section{INTRODUCTION}

Solow ${ }^{(1)}$ stated that, "Malocclusion is not a disease, but it is a morphological variation which may or may not be associated with a pathological condition". Prevalence and types of malocclusion have been used as an important tool in diagnosis-treatment planning procedures, as well as to facilitate communications

* Assistant prof. of University Dept. Faculty of Dentistry, King Abdel Aziz University Saudi. 
between orthodontist, other specialists and general practitioners. In addition, recording malocclusion within the population would aid in the success of orthodontic treatment. ${ }^{(2,3,4,5)}$

Recording and measuring malocclusion could be divided into two main types: qualitative, for recording diagnostic classification of malocclusion (Angle's system, Ackerman and Proffit and classification of Incisor relationship) and quantitative, to measure the features of a malocclusion ${ }^{(6)}$ (PAR, IOTN indices and Little index etc.). Orthodontic literature contains ample studies involving different malocclusion features and treatment need of western Europeans and other ethnic groups. From these features, many variables were recorded such as classification of malocclusion, crowding, spacing, and overjet, in addition to overbite, cross bite and dental arch form ${ }^{(6,7,8)}$.

The quest of dental arch form has interested many disciplines in dentistry. Determination of the dental arch form involves different Algebraic shapes, geometric forms and mathematical formulae. (2,3,7,16) These included Catenary curve $^{(10)}$, average (ovoid), taper (narrow) and square (broad) dental arch shapes $^{(2,3)}$, Geometric (parabola, ellipse, hyperbola and trifocal ellipse) ${ }^{(11,12)}$ While application of computer generated mathematical formulae (quadratic, quartic, cubic spline six degrees, Ricketts' Pentamorphic arches, beta function

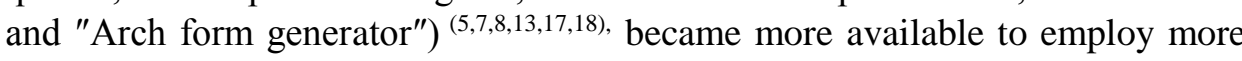
accurate representation of individualized arch form, especially with the quick advancement of computer software, anyhow, the literature shows that there is a lack of agreement as to how to describe the dental arch form and which mathematical formula is the most apt for this description.

Orthodontic treatment demand is increasing and well recognized within the Saudi Arabian and other populations. ${ }^{(1,2,3)}$

Different studies have been caried out since the early 80 's on Saudi patients to investigate the malocclusion pattern, frequency and treatment need. Nashashibi et al ${ }^{(19)}$ found in a population in Riyadh that the frequency of Class I was greater than Class II malocclusion and about 5\% of the sample showed Class III malocclusion.

In 1987, Jones ${ }^{(20)}$ conducted a study to investigate the malocclusion and facial types among a Saudi patient sample in Riyadh. In that sample a greater proportion of Class III malocclusion and a tendency for bimaxillary dentoalveolar proclination was noticed. 
The prevalence of different malocclusion features in 500 male schoolchildren was studied by Al-Emran et al ${ }^{(21)}$ in 1990 . They found that $62.4 \%$ of the sample was presented with one or more malocclusion feature related to dentition, occlusion, or space. Few years later Bulkhi and Zahrany ${ }^{(3)}$ investigated the pattern of different malocclusion features in Saudi patients attending for orthodontic treatment at the College of Dentistry, KSU, Riyadh. They found that the most encountered Angles type of malocclusion was Class I (69.3\%) followed by Class II division 1 (12.2\%), Class II division $2(5 \%)$ and (10 \%) for Class III. With regard to dental arch form, they found that $76.1 \%$ of the sample had an ovoid shape while $14.4 \%$ and $9.5 \%$ had Square and Narrow shape arches respectively.

The previous studies were limited to the district where the studies were performed and were affected by life style in these areas. Therefore, the purpose of this study was to investigate the prevalence of features of malocclusion (Angle Classification, arch form, incisor Classification, median diastima, dental midline discrepancy, crowding and spacing,) among Saudi Arabian patients attending for Orthodontic treatment at the Faculty of Dentistry, K.A.A.U, Jeddah, Saudi Arabia.

\section{Materials and methods}

Study casts of eighty four males and ninety three females Saudi Arabian patients were selected randomly from Orthodontic records using table of random number. The average age for males was 15.3 and for females was 15, ranging from 12 to 23 years for both genders.

\section{Criteria for Dental Cast selection}

- All permanent teeth present, exclusion of third molar.

- Free of restorative treatment other than Class1 restorations.

- Free of air bubbles or fractured teeth.

- No previous orthodontic treatment.

- The casts showing malformed or ectopically erupted teeth were excluded from the sample

- All observations were evaluated under natural and neon light.

Eyeballing method of observation was used to classify the type of malocclusion and different shapes of dental arch form. The type of malocclusions was classified according to Angle's classification system. The dental arch form classification was described according to the mostly common types of description as Ovoid (average), Taper (narrow) shape and Square (broad) shape arches ${ }^{(2,3)}$. 
The recorded variables were as follow:

1. Malocclusion classification: was performed according to Angle's classification system $^{(2)}$.

2. Arch form: classified according to the Categories of Ovoid (average), Taper (narrow) and Square (broad) arch shapes ${ }^{(2,3,8)}$.

3. Incisor classification: was performed according to the British Standards Institute (1983), 4492 Classification incisor relationship

\section{Malocclusion relationships}

Included the followings:

Midline diastema: was registered when there was spacing in between the contact points of upper central incisors of more than $0.5 \mathrm{~mm}^{(3)}$.

Overbite: Cases were either open bite cases when an obious lack of overlap was noticed. The over bite was recorded as decreased, normal or deep when the overbite was $0-30 \%, 30-70 \%$ or more than $70 \%$ respectively. ${ }^{(6)}$.

Crowding: the cases were classified into normal to mild, moderate or severe crowding when the space deficiency was 2-3 mm, 3-5 $\mathrm{mm}$ and more than 5 $\mathrm{mm}$ respectively ${ }^{(22)}$

Spacing: was calculated if it was $2 \mathrm{~mm}$ or more ${ }^{(22)}$

The dental cast measurements (crowding, spacing and midline shift) were performed using digital calliper (mitutoyo, Japan).calibrated to the nearest $0.03 \mathrm{~mm}$. Double determination (Dahlberg) method was used for all variables to determine the intraobserver error and it was found to be $( \pm 0.93 \mathrm{~mm})$. A modified six section technique ${ }^{(17)}$ was employed to determine the arch perimeter.

Statistical analysis (descriptive and comparative) was carried out using the commercial statistical package (SPSS 10.0; SPSS, Chicago, Ill).

\section{RESULTS}

\section{Malocclusion classification (Angle):}

In Table (1) and figure 1, the results show the frequency and percentages of the different classes of malocclusion for both males and females. In males, it was $41.7 \%$ for Class I and $48.8 \%$ for Class II division 1, and $9.5 \%$ for Class III. In females it was $48.4 \%$ for Class I, $41.9 \%$ for class II division 1 and $9.7 \%$ for Class III malocclusions.

Pearson correlation tests revealed weak correlation. 
Egyptian

Orthodontic Journal

\section{Arch form:}

Table (2) and figures 2 and 3 show the frequency and percentage of the different arch forms recorded for both males and females. In lower arch of males, $91.7 \%$ were ovoid, and $4.8 \%$ were narrow. For the upper arch, the narrow shape arches showed a higher $(38.1 \%)$ percentage, while the ovoid shapes were $57.1 \%$. In females, the different arch forms are also presented in table (2). In the lower arch, $89.2 \%$ were ovoid, while narrow arches were $8.6 \%$ and only $2.2 \%$ had square arches. However, in the upper arch, $66.7 \%$ were ovoid and $24.7 \%$ were narrow arches. Only $8.6 \%$ had square arches. There was no statistical significant difference regarding the Classes of malocclusion, $(\mathrm{Z}=$ $0.34,0.83$ and 1.81) for Class I, II and III respectively.

The Chi square Correlation between the three types of Classification and arch form is shown in table (3). In males upper arch the highest Percentage of Ovoid arch shape was detected among Class I (52.8\%) followed by Class II $(42.5 \%)$ and Class III (37.5\%) with statistically significant difference $(\mathrm{P}=0.003)$. Narrow arch form showed statistically significant difference $(\mathrm{P}=0.010)$ While in lower arch form highest Percentage of Ovoid arch shape was detected among Class III (100\%) followed by Class II(92.5\%) and Class I $(49.4 \%)$ with high statistically significant difference $(\mathrm{P}=0.000)$.

In table (4) females upper arch the highest Percentage of Ovoid arch shape was detected among Class I (65.9\%) followed by Class II $(55 \%)$ and Class III $(33.3 \%)$ with statistically significant difference $(\mathrm{P}=0.000)$. Also Narrow arch form showed statistically significant difference $(\mathrm{P}=0.020)$. While in lower arch form the highest percentage of Ovoid arch shape was detected among Class II $(87.5 \%)$ followed by Class I $(81.8 \%)$ and Class III (66.7\%) with high statistically significant difference $(\mathrm{P}=0.000)$ For narrow arch form showed no significant difference $(\mathrm{P}=0.607)$ among the three different malocclusion Classes.

Table 1: Frequency and percent for Angle's classification for both males and females

\begin{tabular}{|l|c|c|c|c|}
\hline \multirow{2}{*}{} & \multicolumn{2}{|c|}{ Males } & \multicolumn{2}{c|}{ Females } \\
\cline { 2 - 5 } & Number & $\%$ & Number & $\%$ \\
\hline Class I & 35 & $41.7 \%$ & 45 & $48.4 \%$ \\
\hline Class II div 1 & 41 & $48.8 \%$ & 39 & $41.9 \%$ \\
\hline Class III & 0.0 & $0.0 \%$ & 0.0 & $0 \%$ \\
\hline Total & 8 & $9.5 \%$ & 9 & $9.7 \%$ \\
\hline
\end{tabular}

Volume 30 - December 2006 
Egyptian

Orthodontic Journal

Table 2: Frequency and percent of the different arch forms recorded for both males and females.

\begin{tabular}{|l|c|c|c|c|}
\hline \multirow{2}{*}{ Ovoid } & \multicolumn{2}{|c|}{ Males } & \multicolumn{2}{c|}{ Females } \\
\cline { 2 - 5 } & Upper & Lower & Upper & Lower \\
\hline Narrow & $48(57.1 \%)$ & $77(91.7 \%)$ & $52(66.7 \%)$ & $83(89.2 \%)$ \\
\hline Square & $32(38.1 \%)$ & $4(4.8 \%)$ & $23(24.7 \%)$ & $8(8.6 \%)$ \\
\hline Total & $4(4.8 \%)$ & $3(3.6 \%)$ & $8(8.6 \%)$ & $2(2.2 \%)$ \\
\hline
\end{tabular}

Table 3: Frequency of different arch forms in different types of malocclusion in males (N.S= Not significant, $*$ significant at $5 \%$ level)

\begin{tabular}{|c|c|c|c|c|c|}
\hline \multicolumn{2}{|c|}{ Males } & $\begin{array}{c}\text { Class I } \\
\text { N (36) }\end{array}$ & $\begin{array}{c}\text { Class II } \\
\text { N (40) }\end{array}$ & $\begin{array}{c}\text { Class III } \\
\text { N (8) }\end{array}$ & P value \\
\hline \multirow{4}{*}{ Upper } & Ovoid & $\mathbf{1 9}(52.8 \%)$ & $\mathbf{1 7}(42.5 \%)$ & $\mathbf{3}(37.5 \%)$ & $0.003 *$ \\
\cline { 2 - 6 } & Narrow & $\mathbf{1 6}(44.5 \%)$ & $\mathbf{2 0}(50.0 \%)$ & $\mathbf{5}(62.5 \%)$ & $0.01 *$ \\
\cline { 2 - 6 } & Square & $\mathbf{1}(2.7 \%)$ & $\mathbf{3}(7.5 \%)$ & $0.0(0.0 \%)$ & $0.317 \mathrm{NS}$ \\
\hline \multirow{3}{*}{ Lower } & Ovoid & $\mathbf{3 4}(49.4 \%)$ & $\mathbf{3 7}(92.5 \%)$ & $\mathbf{8}(100 \%)$ & $0.000 *$ \\
\cline { 2 - 6 } & Narrow & $\mathbf{2}(5.6 \%)$ & $\mathbf{3}(7.5 \%)$ & $0.0(0.0 \%)$ & $0.655 \mathrm{NS}$ \\
\cline { 2 - 6 } & Square & $0.0(0.0 \%)$ & $0.0(0.0 \%)$ & $0.0(0.0 \%)$ & \\
\hline
\end{tabular}

Table 4: Frequency of different arch forms in different types of malocclusion in females. $\left(\right.$ N.S $=$ Not significant, ${ }^{*}$ significant at $5 \%$ level $)$

\begin{tabular}{|c|c|c|c|c|c|}
\hline \multicolumn{2}{|c|}{ Females } & $\begin{array}{c}\text { Class I } \\
\text { N (44) }\end{array}$ & $\begin{array}{c}\text { Class II } \\
\text { N (40) }\end{array}$ & $\begin{array}{c}\text { Class III } \\
\text { N (9) }\end{array}$ & P value \\
\hline \multirow{4}{*}{ Upper } & Ovoid & $\mathbf{2 9}(65.9 \%)$ & $\mathbf{2 2}(55 \%)$ & $\mathbf{3}(33.3 \%)$ & $0.000 *$ \\
\cline { 2 - 6 } & Narrow & $\mathbf{1 0}(22.7 \%)$ & $\mathbf{1 8}(45 \%)$ & $\mathbf{5}(55.6 \%)$ & $0.020 *$ \\
\cline { 2 - 6 } & Square & $\mathbf{5}(11.4 \%)$ & $0.0(0.0 \%)$ & $\mathbf{1}(11.1 \%)$ & $0.102 \mathrm{NS}$ \\
\hline \multirow{3}{*}{ Lower } & Ovoid & $\mathbf{3 6}(81.8 \%)$ & $\mathbf{3 5}(87.5 \%)$ & $\mathbf{6}(66.7 \%)$ & $0.000 *$ \\
\cline { 2 - 6 } & Narrow & $\mathbf{6}(13.6 \%)$ & $\mathbf{5}(12.5 \%)$ & $\mathbf{3}(33.3 \%)$ & $0.607 \mathrm{NS}$ \\
\cline { 2 - 6 } & Square & $\mathbf{2}(4.5 \%)$ & $0.0(0.0 \%)$ & $0.0(0.0 \%)$ & - \\
\hline
\end{tabular}

\section{Incisor Classification:}

Table (5) shows the frequency and percentage of the incisor Classification in males and females. In males the percentage was $34.5 \%$ for Class I, $57.1 \%$ for Class II and $8.3 \%$ for Class III. While in females the percentages were $43 \%$, $52.7 \%$ and $4.3 \%$ for Class I, II and III respectively. 
Egyptian

Orthodontic Journal

Table (5): frequency and percentage of Incisor Classification for both males and females.

\begin{tabular}{|c|c|c|}
\hline \multirow{2}{*}{ Class } & MALES & FEMALES \\
\cline { 2 - 3 } & Frequency (\%) & Frequency ( \%) \\
\hline Class I & $29(34.5 \%)$ & $40(43 \%)$ \\
\hline Class II & $48(57.1 \%)$ & $49(52.7 \%)$ \\
\hline Class III & $7(8.3 \%)$ & $4(4.3 \%)$ \\
\hline Total & $84(100 \%)$ & $93(100 \%)$ \\
\hline
\end{tabular}

\section{Malocclusion relationship:}

The data collected on malocclusal abnormalities are presented in table (5) for males and females. These data included the presence of midline diastema, crowding and spacing and amount of overbite. Midline diastema was present in $75 \%$ of males and $70 \%$ of females. Only eight males and females showed an open bite $(9.5 \%$ and $8.6 \%$ respectively). Deep bite was noticed in $33.3 \%$ of males and $29 \%$ of females. Regarding the space available in the arches, it was noticed that there was a similar distribution between the different crowding categories in both maxilla and mandible in males and females.

Table 6: The percentages of different malocclusion variables for both males and females

\begin{tabular}{|l|c|c|c|c|}
\hline \multirow{2}{*}{ Midline } & \multicolumn{2}{|c|}{ Males (n=84) } & \multicolumn{2}{c|}{ Females (n=93) } \\
\cline { 2 - 5 } diastema & maxilla & mandible & maxilla & mandible \\
\hline Present & & & & \\
Absent & $63(75 \%)$ & & $70(75.3 \%)$ & \\
\hline Overbite & $21(25 \%)$ & ----------- & $23(24.7 \%)$ & ------------- \\
Open bite & $8(9.5 \%)$ & & & \\
Decreased & $31(36.9 \%)$ & ------------ & $32(34.4 \%)$ & -------------- \\
Normal & $17(20.2)$ & & $26(28 \%)$ & \\
Deep bite & $28(33.3 \%)$ & & $27(29 \%)$ & \\
Crowding & & & & \\
Spacing & $13(15.5 \%)$ & $16(19 \%)$ & $22(23.7 \%)$ & $17(18.3 \%)$ \\
Normal & $30(35.7 \%)$ & $26(31 \%)$ & $26(28 \%)$ & $36(38.7 \%)$ \\
Moderate & $17(20.2 \%)$ & $19(22.6 \%)$ & $16(17.2 \%)$ & $21(22.6 \%)$ \\
Severe & $24(28.6 \%)$ & $23(27.4 \%)$ & $29(31.2 \%)$ & $19(20.4 \%)$ \\
\hline
\end{tabular}

Volume 30 - December 2006 


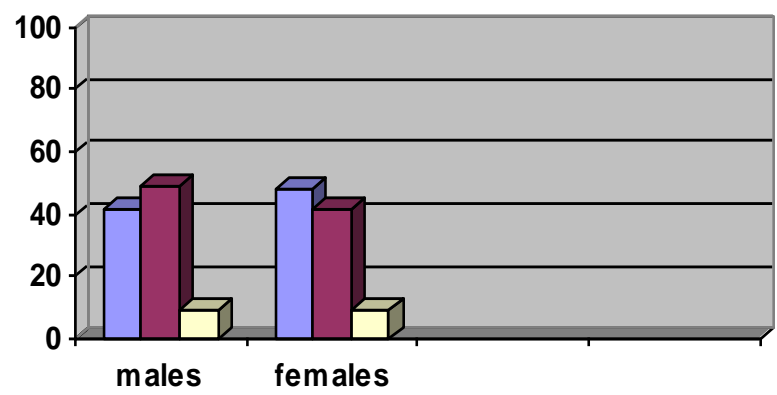

$\square$ Class

$\square$ Class II div 1

$\square$ Class III

Figure 1: The distribution of classes of malocclusion among males and females

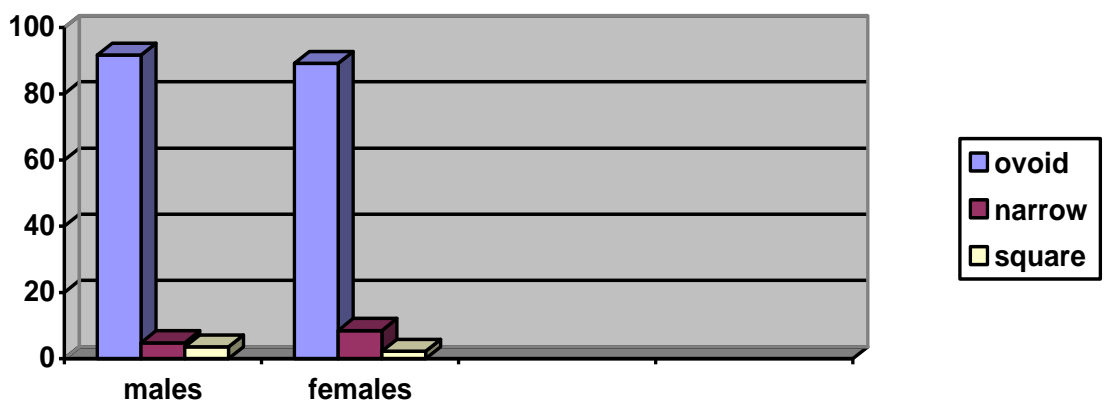

Figure 2: distribution of different mandibular arch forms in males and females

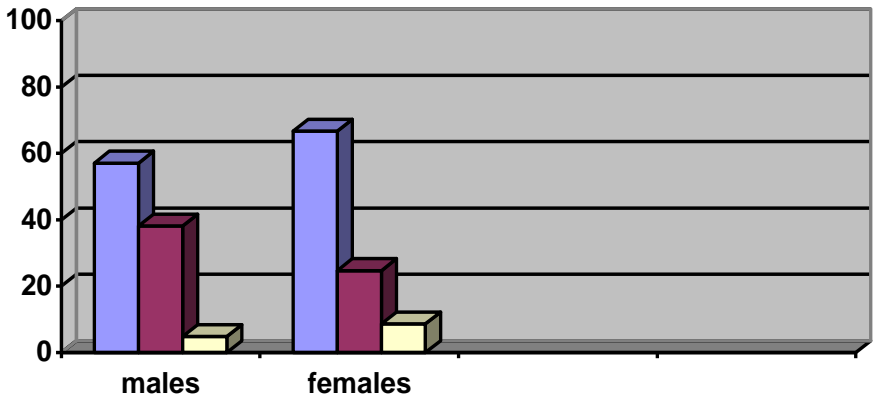

Figure 3: distribution of different maxillary arch forms in males and females 
Egyptian

Orthodontic Journal

\section{DISCUSSION}

Identification of the patient's malocclusion Class (Angle's Classification) is used widely to define malocclusion and for communication between orthodontists. This also shed a light for a future study plan to include all cases attending for orthodontic treatment. In this preliminary investigation the data is representing the clinical observation of the author who was previously a member of Orthodontic division in Riyadh Dental School and postulated that prevalence of malocclusion was almost the same in Jeddah, (western of Saudi Arabia) as in Riyadh. The prevalence of malocclusion in Jeddah is relatively different, and this may have resulted through interbreeding between groups of multi ethnic background who lived in this region. (2). Furthermore, other environmental factors could play a role.

Malocclusion classification (Angle): In this study the frequency distribution of Class II (48.8\%) was found to be more than Class I malocclusion $(42.7 \%)$ in males. While in females the Class I is marginally higher $(48.4 \%)$ than Class II malocclusion (41.9\%). However, the frequency of Class III malocclusion in this study was found to be more frequently occurring than what has been reported by Bulkhi and Zahrany ${ }^{(3)}$ (9.5\% and $9.7 \%$ for males and females respectively). For the frequency of Class III, this study confirmed those reported by Jones ${ }^{(20)}$ Despite the sample size of this study, the findings do not support the previous studies of Nashashibi et al ${ }^{(19)} \mathrm{Al}$-Emran et al ${ }^{(21)}$ and Bulkhi and Zahrany ${ }^{(6)}$

Arch form: The frequency distribution of the three types of arch form observed in the present study was predominantly showing dissimilar frequency levels. In this study the upper and lower arches were described according to the three types of dental arch form (Ovoid, Narrow and Square) which was found to be in agreement with the results of Bulkhi and Zahrany ${ }^{(3)}$ only in the frequency of Ovoid arch. The Constricted (Narrow) upper arch was more evident in males (57.4\%) than females (35.8\%), which was consistent with the higher percentage of males Class II malocclusion. While in females Narrow lower arch form was more frequently observed. Although, the description of the arch form employing eyeballing method is subjective, but a computer method is obviously is more accurate. In this study the attempt was made to present the prevalence of arch form in Jeddah area in preparation for a larger study including normal shape arches using a computer method.

Incisor Classification: This Classification nowadays is widely used, and in this study it showed that, it gave more sensitive description to malocclusion 
because it is based upon upper and lower incisal relationship in which the normal and abnormal relation of the incisors is detected more clearly. In fact the anteroposterior incisor relationship can be looked at quantitatively as an overjet, and if the overjet is increased positively then theoretically speaking, the molar relation could be also in Class II position, but this is not always the case, and this situation has always been confusing because molar relationship is not included in this incisor classification. Furthermore, in Angle's Classification we always look at the molar position, and there is no precise scale as to what limit, one could classify Angle's Class I.

Malocclusal relationship: Within these variables the highest prevalence was in females midline shift $(75.5 \%)$ and $(69.9 \%)$ in males, which was much higher than that reported in earlier Saudi sample studies ${ }^{3,19,20,21}$ The second most common prevalence was dental crowding, which was higher in females than in males and was greater in females lower arch than in males (See table 7). This reflects what was found in this study; the constriction of upper arch in males and lower arch in females. Previous studies reported less prevalence of dental crowding and more spacing compared to this study. The prevalence of midline diastima was more frequent in females than in males, but it is comparable to the study of Bulkhi.K and Zahrany ${ }^{(3)}$.

\section{CONCLUSION}

- The frequency of Class II malocclusion was the highest in males, and Class I was the highest in females than the other Classes of malocclusions.

- Class III was relatively high as compared to the previous studies. In addition, in this study it was more dominant in females than in males. (not statically significant)

- Constricted upper arch (Narrow) is more evident in males than in females, which is consistent with the higher percentage of Class II malocclusion. Constricted lower arch form was higher in females than males

- Dental midline shift and Crowding in both genders is the most prevalent variable among malocclusal features respectively.

- The pattern of malocclusion in Jeddah, presented in this study sample seems to be different from that reported in Riyadh area. A prospective study is necessary to reach a conclusion about the pattern of malocclusion and the etiological factors behind it. 
Egyptian

Orthodontic Journal

\section{REFERENCES}

1. Solow B. (1970): Computer analysis of malocclusion prevalence. International Dental Journal; pp,633-641.

2. Proffit W.R.and H.W. Fields, JR. (2000): Contemporary Orthodontics, Third Edition, section II (5) PP: 113.

3. Bulkhi.K and Zahrany. A(1994): The pattern of malocclusion in Saudi Arabian patients attending for orthodontic treatment at the college of dentistry, king Saud University, Riyadh, The Saudi Dental Journal, Volume 6,Number 3,September.

4. Morton I. Katz (1992): Angle Classification revisited1: Is current use reliable? American Journal of Ort hodontics and Dentofacial Orthopaedics, Aug. (173-179) VIEW POINT.

5. Amm EW, Bou-Serhal (2003): The form of the dental arch according to the Tweed-Merrifield philosophy: individualization and attempt at standardization. (Abstract) L'orthodontie Francaise, Dec; 74(4):481-98.

6. Silva, R.G. and Kang, D.S. (2001): Prevalence of malocclusion among Latino adolescent. American Journal of Orthodontics and Dentofacial Orthopaedics, Vol. 119, No. 3, 313-15.

7. Braun S., Hnat W.P.; Fender D.E. and Legan H.L. (1998): The form of human dental arch. Angle Orthodontist, Vol68, No1, 29-36

8. Noroozi H., Hosseinzadeh T.and Saeeda R. (2001): The dental arch form revisited. Angle Orthodontist, Vol71, No5, 386-389.

9. Scott, J.H, (1957): The shape of the dental arches, Journal of dental research, vol. 36, 996-1003.

10. Musich, D.R. and Ackerman, J.T.(1973): The catinometer, a reliable device for estimating dental arch perimeter, American Journal of Orthodontics, Vol. 63, 366-375.

11. Lu, K.H. (1964): Analysis of dental arch symmetry, Abstract, Journal of dental research, Vol. 43, 780.

12. Lu, K.H. (1966): An orthogonal analysis of the form symmetry and symmetry of the dental arch. Archive. Oral Biology, Vol. 11, 1057-1069.

13. Mills, L.F. and Hamilton, P.M. (1965): Epidemiological studies of malalighnment- a method for computing dental arch circumference, .Angle Orthodontist, Vol: 35,244-248. 
14. Neilans, L.C. (1968): A computerizes analysis of human dental arch form as compared to the catenary curve. MSc thesis, Temple University, Philadelphia, U.S.A.

15. Currier, J.H. (1969): A computerizes geometric analysis of human dental arch form. American Journal of Orthodontics, Vol.56: 164-179.

16. Angle, E.H. (1899): Classification of malocclusion. Dental Cosmos, 41,248-64

17. Murshid, Z.A.S. (1991): Computer aided measurement of dental casts with special reference to crowding and arch form. M.PH. thesis, Kings College, London University, U.K.

18. Begole E.A. (1979): A computer program for the analysis of dental arch form using the cubic spline function. Computer programs Biomedical, vol.10, 136-142.

19. Nashashibi IA, Darwish SK, El-Rasheed K. (1983): Prevalence of malocclusion and treatment need in Riyadh (Saudi Arabia). Odontostomatol Trop, 6: 209-214.

20. Jones WR (1987): Malocclusion and facial types in a group of Saudi Arabian patients referred for Orthodontic treatment: A preliminary study. British Journal of Orthodontics, July; 14(3): 143-146.

21. Al-Emrann, S, Wisth PJ, Boe, OE (1990): Prevalence of malocclusion and need for orthodontic treatment in Saudi Arabia. Community Dent Oral Epidemiol, Oct; 18(5): 253-255.

22. Bjork, A., Krebs, A.A. and Solow, B. (1964): A method for epidemiological registration of malocclusion. Acta Odontol. Scand. Vol 22, 27-41.

23. Foster T.D, Hamilton M.C. and Lavelle, C.L B (1970): A study of Dental Arch crowding in four age groups. The Dental practitioner, Vol 21, No1.

24. Tang, E.L.K. and Wei, S.H.Y. (1993): Recording and measuring malocclusion: A review of literature. American Journal of Orthodontic and Dentofacial Orthopaedics, Vol. 103, No. 4, 344-51.

25. Brigit Thilander, Lucia Pena, Clementina Infante, Sara Stella Parada and Clara de Mayorga (2001): Prevalence of malocclusion and orthodontic treatment need in children and adolescents in Bogota, Colombia. An epidemiological study related to different stages of dental development. European Journal of Orthodontics, Vol. 23, 153-167.

26. Morton I. Katz (1992): Angle Classification revisited 2:P A modified Angle Classification. American Journal of Orthodonitcs and Dentofacial Orthopaedics, Sep. (227-284) VIEW POINT. 